\title{
Knowledge and attitudes of doctors on medical ethics in a teaching hospital, Manipur
}

AKOIJAM BROGEN S', BISHWALATA RAJKUMARI', JALINA LAISHRAM', AKOIJAM JOY²

${ }^{1}$ Community Medicine Department, Regional Institute of Medical Sciences, Imphal, Manipur 795004 INDIA email: brogen@rediffmail.com ${ }^{2}$ Department of Physical

Medicine and Rehabilitation, Regional Institute of Medical Sciences, Imphal, Manipur 795004 INDIA

\begin{abstract}
This study aimed to assess the knowledge of, and attitudes to, medical ethics among doctors in the Regional Institute of Medical Sciences (RIMS), Imphal, Manipur. It also looked at the association between levels of knowledge and selected variables.

A self-administered structured questionnaire was distributed to all doctors working in RIMS, Imphal between September and October 2007. 315 of 440 (71.6\%) doctors contacted, responded. $62.2 \%$ of respondents (196) were below 35 years of age. $22.5 \%$ (71) were faculty members . 98.7\% (311) had heard of the Code of Medical Ethics but only 188 (59.7\%) had read it, even in part. 69.2\% (218) felt that the undergraduate curriculum on medical ethics was not adequate. $10.5 \%$ (33) could describe what medical professionalism meant. Knowledge of medical ethics was higher among those who were over 35 years of age, those who graduated before 1999 and those having higher educational qualifications.
\end{abstract}

The doctors in this survey lacked adequate and detailed knowledge on the code of ethics, though most of them had read it once. There is a need to sensitise doctors on medical ethics and professionalism.

\section{Introduction}

Ethics has been defined as "the moral principles that govern a person's behaviour or how an activity is conducted" and medical ethics as "the branch of knowledge concerned with moral principles" (1). The application of ethics to medical practice dates back to ancient civilisation as even today, all medical graduates must swear symbolic adherence to the Hippocratic oath. Codes of conduct and laws regulating the profession are laid down from time to time (2).

There has been growing public awareness regarding the ethical conduct of medical practitioners, and complaints against physicians appear to be escalating. This may reflect an increase in unethical practices by doctors or increasing public awareness of such unethical practices. In medicine, professionalism connotes not only knowledge and skills, but also character, especially compassion and ethics (3). It is a commitment to subordinate our self-interest to the interest of patients and it is the foundation of trust upon which our social contract as physicians rests (4).
The recent increase in litigation against doctors is an issue of immediate concern. The reasons for this are social, economic, professional and judicial. Social factors include increasing media awareness about medical facts and fallacies, professional accountability, and rights of patients in terms of information, decision-making and assessing outcomes. Negative publicity in the media about the profession has done further damage (5). Moreover, doctor-patient confrontations have been increasing in the recent past in the state $(6,7,8)$. Doctors should familiarise themselves with the regulations and laws that concern their practice. Hence, this study was taken up to assess the knowledge and attitude of medical ethics and professionalism among doctors working in the Regional Institute of Medical Sciences (RIMS), Imphal, Manipur. RIMS is the only teaching hospital with super-speciality departments in the northeastern state of Manipur. It caters to students from seven of the eight northeast states, admitting 100 undergraduate students per year. The institute offers post graduate courses in all subjects taught at the MBBS level.

\section{Materials and methods}

A cross sectional study was conducted at the RIMS in September and October 2007. All the doctors including interns and house officers were included in the study. Those who were on leave refused to participate and those who where not available on the third visit were excluded from the study.

A structured, self administered questionnaire containing 35 items relating to knowledge of and attitudes to medical ethics was devised and pre-tested. Minor changes were made to make the final instrument. The first part of the questionnaire consisted of the demographic characteristics of the respondents, such as educational qualification, year of graduation, council of registration and post held. The second part consisted of questions on their knowledge of ethics and professionalism. In the third part, respondents were required to state if they agreed or disagreed with various statements concerning ethical conduct, confidentiality, informing patients about wrongdoings, informed consent, abortion, etc. The responses were provided in a Likert scale ranging from 1 to 5 (1-strongly disagree, 2-disagree, 3-not sure, 4-agree and 5-strongly agree). For the knowledge-based eleven questions, a score of either 0 or 1 was assigned to each question. Then the score was summed up and it ranged from 
0 to 11 . For the purpose of analysis, those who scored $\geq 75$ th percentile of the summated score were considered to possess adequate/average knowledge about medical ethics, and those who scored $<75$ th percentile considered to possess insufficient knowledge about medical ethics.

Descriptive statistics like means, percentages, percentiles and Chi-square significance test were used in the analysis. A probability value of $<0.05$ was considered significant. An analysis was carried out for the attitudinal questions by categorising them into either the "agreed" or the "disagreed" group by leaving "not sure" answers.

Permission to conduct the study was obtained from the institute authority. Oral informed consent was taken from each respondent. Confidentiality was maintained.

\section{Results}

The study covered 574 doctors working in RIMS. Of these 171 were excluded (37 did not give consent, 30 were on leave and 104 were not available on three consecutive visits). Of the 403 eligible doctors, 315 responded and 88 did not return the questionnaires giving a response rate of $78.6 \%$.

\begin{tabular}{|l|c|}
\hline \multicolumn{2}{|c|}{ Table 1: Background characteristics of participants, N (\%) } \\
\hline Age(years) & N(\%) \\
$<35$ & $196(62.2)$ \\
$\geq 35$ & $119(37.8)$ \\
\hline Sex & \\
Male & $192(60.9)$ \\
Female & $123(39.1)$ \\
\hline Qualification & \\
MBBS & $221(70.2)$ \\
Post-MBBS degree & $94(29.8)$ \\
\hline Designation & \\
Faculty & $71(22.5)$ \\
Non-faculty (junior doctors) & $244(77.5)$ \\
\hline Council of registration MCI & $32(10.2)$ \\
Assam Medical Council & $225(71.4)$ \\
Other state councils & $58(18.4)$ \\
\hline Year of graduation & $160(50.8)$ \\
Before 1999 & $155(49.2)$ \\
1999 onwards & \\
\hline &
\end{tabular}

The age of the respondents ranges from 22 to 60 years and the median age of 35 years was used to separate them into two groups. The majority of respondents were below 35 years of age $(196,62.2 \%)$. Males constituted $60.9 \%$ (192) and senior faculty members constituted $22.5 \%$ (71). Around $29.8 \%$ (94) respondents had qualifications higher than MBBS and half the respondents $(160,50.8 \%)$ graduated before 1999. (Table 1)

Most of the respondents $(311,98.7 \%)$ had heard of the Code of Ethics. However, only 188 (59.7\%) had read it once or partially.
Around $76.5 \%$ (241) of the respondents said that they were taught about ethics in medicine in their undergraduate curriculum but $6.3 \%$ (20) could not remember whether or not it was taught. However, the majority $(218,69.2 \%)$ felt that the undergraduate curriculum on medical ethics was not adequate and almost all $(312,99 \%)$ stated that it was necessary to include the Code of Ethics in the undergraduate curriculum. In a multiple response query, the majority $(228,72.3 \%)$ responded that they obtained their knowledge of ethics during their undergraduate training, $29.8 \%(94)$ said that they acquired a knowledge of ethics through experience at work, whereas $33 \%$ (104) stated that they got it through attending lectures, seminars, workshops or continuing medical education (CME).

Only $48(15.3 \%)$ of the respondents correctly answered the question regarding the Medical Council of India $(\mathrm{MCl})$ Code of Ethics guidelines on the required hours of participation by medical professionals in a CME session. 93(29.5\%) responded correctly when asked how long records for indoor patients were to be maintained, $84(26.7 \%)$ could give the correct response regarding the period within which a physician has to produce the records when asked by patients or legal authorities and 165 (52.3\%) responded that it was necessary to display the $\mathrm{MCl}$ registration number in every prescription slip, medical certificate and receipt given to patients. When asked whether healthcare professionals are bound by the Consumer Protection Act of 1986, 236 (74.9\%) gave the correct response. On a multiple response question about why patients ask for disclosure of records, most of the respondents 220(69.8\%) stated that patients want information on the condition and treatment, $140(44.4 \%)$ said that it could be to consult another physician and $117(37.1 \%)$ responded that the patients were considering lawsuits. Around $14.3 \%$ (45) responded that doctors should have adequate knowledge regarding ethics and work accordingly as a precautionary measure against lawsuits.

Around $33.3 \%$ (105) knew of the existence of an ethics committee in RIMS but only 22 (6.9\%) respondents knew the role of the ethics committee. Most of the respondents (150, $47.6 \%$ ) said that they would consult a lawyer or the head of the department or the ethics committee when faced with ethical or legal problems. More than half (59\%) of the respondents replied that the patient's consent was necessary before surgery, laboratory tests and physical examination. But, nearly $3 / 4$ th $(71.7 \%)$ of the respondents answered that consent was necessary for surgery and laboratory tests.

Nearly one third $(95 / 315,30.1 \%)$ of the respondents had adequate knowledge on the code of ethics. Though statistical significance were lacking, knowledge of ethics was higher among the respondents who were more than 35 years of age, those who graduated before 1999, among males and those having higher qualification (Table 2 ). 


\begin{tabular}{|l|c|c|c|}
\hline \multicolumn{3}{|c|}{ Table 2. Knowledge of code of ethics by selected variables } \\
\hline Variable & \multicolumn{2}{|c|}{ Knowledge of ethics } & P-value \\
\hline & $\begin{array}{c}<\text { 75th } \\
\text { percentile }\end{array}$ & $\begin{array}{c}\geq 75 \text { th } \\
\text { percentile }\end{array}$ & \\
\hline Age (years) & $139(70.9)$ & $57(29.1)$ & 0.593 \\
$\leq 35$ & $81(68.1)$ & $38(31.9)$ & \\
$>35$ & & & \\
\hline Sex & $131(68.2)$ & $61(31.8)$ & 0.436 \\
Male & $89(72.4)$ & $34(27.6)$ & \\
Female & & & \\
\hline Qualification & $156(70.6)$ & $65(29.4)$ & 0.658 \\
MBBS & $64(68.1)$ & $30(31.9)$ & \\
Post-MBBS & $21(65.6)$ & $11(34.4)$ & 0.050 \\
\hline Council of registration MCI & $165(73.7)$ & $59(26.3)$ & \\
Assam Medical Council & $34(57.6)$ & $25(42.4)$ & \\
Other state councils & & & \\
\hline Year of graduation & $104(65.0)$ & $56(35.0)$ & 0.057 \\
Before 1999 & $116(74.8)$ & $39(25.2)$ & \\
1999 onwards & & & \\
\hline
\end{tabular}

Only $33(10.5 \%)$ of the respondents could state what medical professionalism means. The majority $(170,54 \%)$ of respondents could not recall any of the contents of the Hippocratic Oath.

The majority of respondents disagreed with the statements that patients should be informed of wrong-doings by doctors (64.4\%) and doctors should refuse to treat uncooperative patients (67.3\%). Again, the majority of respondents disagreed on the statements that doctors should reveal the patient's condition to close relatives irrespective of whether the patient gave permission $(80.0 \%)$ and children should not be treated without the parents' consent (61.9\%). The differences in responses between senior (faculty members) doctors and junior doctors regarding the above statements are shown in Table 3. There was a statistically significant difference between the opinions of senior and junior doctors regarding whether doctors could refuse to treat uncooperative or violent patients, with a significantly higher proportion of senior doctors disagreeing with the statement that doctors could refuse $(P<0.012)$. Although a higher proportion of senior doctors agreed with the statements, there were no significant differences in the strength of the opinions regarding other issues such as whether patients should be informed if a doctor did something wrong, whether close relatives should be informed about a patient's condition, whether seeking consent should be sought from children and whether it was acceptable for a doctor to conduct a legally permissible abortion.

\section{Discussion}

In this study, younger doctors ( $<36 \mathrm{yr}$ ) dominated our sample as they were more in number in the institute. Males outnumbered female doctors in the sample as well as in the institute.

We focused on the MCl's Code of Ethics, 2002, in the questionnaire. It is possible that respondents who refused to participate were more likely to be unaware of the Code of Ethics, 2002, or they were older doctors who thought such a study was testing them. We contemplated using an interview as a tool for the study but because of constraints of time, manpower and unwillingness of respondents, the questionnaire was self-administered. The majority of respondents returned the completed questionnaires in 24 hours. A high percentage of doctors had "heard" and even "read" the Code of Ethics. This could be because the respondents consulted their colleagues or read the code between the time they received the questionnaire and the time that they returned the completed questionnaire. However, questions on specific sections of the Code of Ethics received fewer correct responses, indicating lack of in-depth knowledge about medical ethics.

The majority who reported that the Code of Ethics was taught at the undergraduate level also felt that it was inadequate. This might be because only the section on forensic medicine was taught in undergraduate courses and also because this section was focused on medical jurisprudence. Further, we did not try to validate their claim that they were aware of biomedical ethics from their undergraduate training. The study also highlights the importance of seminars, conferences and continuing medical education as a source of knowledge on biomedical ethics, as around one third in this sample got it from those platforms.

\begin{tabular}{|c|c|c|c|c|c|}
\hline Issues & Designation & $\begin{array}{c}\text { Disagree N } \\
(\%)\end{array}$ & $\begin{array}{c}\text { Agree N } \\
(\%)\end{array}$ & Chi-square & P-value \\
\hline Patients should always be informed of wrong doing by doctors & $\begin{array}{c}\text { Faculty } \\
\text { Junior doctors }\end{array}$ & $\begin{array}{c}37(67.3) \\
166(76.9) \\
\end{array}$ & $\begin{array}{l}18(32.7) \\
50(23.1)\end{array}$ & 2.14 & 0.143 \\
\hline Close relatives should always be told of the patient's condition & $\begin{array}{c}\text { Faculty } \\
\text { Junior doctors }\end{array}$ & $\begin{array}{c}7(10.6) \\
40(17.1) \\
\end{array}$ & $\begin{array}{c}59(89.4) \\
194(82.9) \\
\end{array}$ & 1.690 & 0.20 \\
\hline Children should never be treated without the parent's consent & $\begin{array}{c}\text { Faculty } \\
\text { Junior doctors }\end{array}$ & $\begin{array}{l}23(34.3) \\
82(35.2)\end{array}$ & $\begin{array}{c}44(65.7) \\
151(64.8)\end{array}$ & 0.017 & 0.896 \\
\hline Doctors should refuse to treat uncooperative/violent patients & $\begin{array}{c}\text { Faculty } \\
\text { Junior doctors }\end{array}$ & $\begin{array}{c}58(86.6) \\
154(71.3) \\
\end{array}$ & $\begin{array}{c}9(13.4) \\
62(28.7) \\
\end{array}$ & 6.345 & 0.012 \\
\hline If the law allows abortion, doctors cannot refuse to do abortion & $\begin{array}{c}\text { Faculty } \\
\text { Junior doctors }\end{array}$ & $\begin{array}{c}35(59.3) \\
150(69.8) \\
\end{array}$ & $\begin{array}{l}24(40.7) \\
65(30.2)\end{array}$ & 2.30 & 0.129 \\
\hline
\end{tabular}

* missing value due to 'not sure'category 
The doctors in the sample lacked proper and detailed knowledge on the contents of the Code of Ethics, 2002; few correct responses were elicited to questions on how records were to be maintained, whether records were to be produced on demand and how many hours of participation were required in CMEs. Even when more than half the respondents correctly answered questions on how registration details were to be displayed and whether doctors were covered under the Consumer Protection Act, their responses could not be considered satisfactory as such things should be known by all doctors.

Though nearly one third knew about an ethics committee in RIMS, very few knew about the role played by the committee. This could be because of the very limited role played by the ethics committee in the institute. The committee looks after ethical issues of research only.

Since medical ethics is not taught in the undergraduate level in almost all medical colleges, it is more likely that senior doctors (either by age or qualification) and those who graduated before 1999 have better knowledge in medical ethics either by experience or by attending more CMEs, conferences and workshops. The same explanation could be given for the findings in this study. A study, though from outside the country, also showed the same findings in a similar set up (9). The finding that males and those who registered with other State Medical Councils other than the $\mathrm{MCl}$ and the Assam Medical Council had better knowledge of the Code of Ethics could be a chance finding. A short test on the Code of Ethics could be considered while getting registration from any registration body.

Patient-doctor mistrust was evident, as the respondents opined that medical records are demanded by the patients' parties for lawsuits (37.1\%) and to seek the advice of another physician $(44.4 \%)$

From the responses to the attitudinal questions, it seemed that doctors were generally not in favour of revealing doctors' mistakes to patients. Doctors were also likely to lean towards revealing a patient's condition to the close relative, irrespective of whether or not the patient's permission was sought. Breach of confidentiality is against ethics but at times as a doctor, in the larger interest of the public, it may be acceptable. However, how much the opinions of the respondents were influenced by considering such situations in this study is hard to say. There was no statistically significant difference between the faculty members and junior doctors in the opinions, except in their opinions regarding treating uncooperative patients. Junior doctors were more likely to be in favour of not negotiating with, or treating, uncooperative patients.

\section{Conclusion}

There was lack of proper and detailed knowledge on the MCl's Code of Ethics among doctors in RIMS, though a little more than half of them had read it once or partially. There is a need to sensitise them to the Code of Ethics and to medical ethics in general. A test on the code at the time of registration could be considered.

Acknowledgement: We wish to thank the ICMR, New Delhi and $\mathrm{NIH}$ (US) for allowing us to join the long term training on bioethics in India and helping us to undertake this study

\section{References}

1. Catherine Soanes (editor). The Compact Oxford Reference Dictionary. Oxford University Press;2001[c16].

2. $\mathrm{MCl}$. Indian Medical Council. Professional Conduct, Etiquette and Ethics Regulations, 2002. Gazette of India. 2002 Apr 6;Part-III-Sec-4.

3. Moser RH. A few thoughts about professionalism (editorial). South Med J. 2000; 93:1132-3.

4. Brennan T, Blank L, Cohen J, Kimball H, Smelser N, Copeland R, et al. Medical professionalism in the new millennium: a physician charter. Ann Intern Med [Internet].2002 Feb 5 [cited 2009 Aug 13]; 136(3):243-6. Available from: http://www.annals.org/cgi/content/full/136/3/243

5. Reddy C. Medical ethics. Indian J Dent Res [Internet]. 2007 [cited 2009 Aug 13]; 18 (2):47. Available from: http://www.ijdr.in/text. asp?2007/18/2/47/32418

6. Patient-party clash with docs, RIMS shut. The Sangai Express [Internet] 2007 Feb 19 [cited 2009 Aug 13]. Available from: http://e-pao.net/ epArcDisplay.asp?src $=200207$

7. General strike called on Feb 23 over RIMS death The Imphal Free Press [Internet].2007 Feb 22 [cited 2009 Aug 13]. Available from: http://www. kanglaonline.com/index.php?template=news_archive_result\&ldoc_Se ssion=f06774f07c9a7a57c3c232ced0c34676

8. RIMS inquiry committee to probe patient's death. The Imphal Free Press[Internet]. 2007 Apr 28 [cited 2009 Aug 13]. Available from: http://www.kanglaonline.com/index.php?template=news_archive_ result\&Idoc_Session=f06774f07c9a7a57c3c232ced0c34676

9. Hariharan S, Jonnalagadda S, Walrond E, Moseley H. Knowledge, attitudes and practice of healthcare ethics and law among doctors and nurses in Barbados. BMC Medical Ethics. [Internet]. 2006 Jun 9 [cited 2009 Aug 13];7: [About 8p.]. Available from: http://www.biomedcentral. com/1472-6939/7/7 